\title{
Factors Associated with the Nutritional Status among Male Workers of Iron and Steel Industries in Bara District, Nepal
}

\author{
Raj Kumar Sangroula (iD, Hari Prasad Subedi $\mathbb{D}^{D}$, and Kalpana Tiwari \\ College of Applied Food and Dairy Technology, New Baneshwar, Kathmandu, Nepal \\ Correspondence should be addressed to Raj Kumar Sangroula; raj.sang18@gmail.com \\ Received 4 January 2020; Revised 8 April 2020; Accepted 18 May 2020; Published 28 June 2020
}

Academic Editor: Mohammed S. Razzaque

Copyright (C) 2020 Raj Kumar Sangroula et al. This is an open access article distributed under the Creative Commons Attribution License, which permits unrestricted use, distribution, and reproduction in any medium, provided the original work is properly cited.

\begin{abstract}
Background. Overweight and obesity are major serious public health problems, since their prevalence is accelerating rapidly not only in developed but also in developing countries. The aim of this study was to find out the factors associated with the nutritional status of the industrial workers in Bara District of Nepal. Methods. An industry-based analytical cross-sectional study was conducted among the 271 male workers using pretested semistructured questionnaires, food frequency questionnaire, 24-hour recall method, and anthropometric measurement after obtaining informed consent from the workers. For the categorical independent variables, bivariate and multivariate regression tests were used for the analysis, and for numerical independent variables, Student's $t$-test was used. A $P$ value less than 0.05 was considered significant. Ethical approval was taken from the Research Committee of the College of Applied Food and Diary Technology (CAFODAT). Results. Overweight /obesity was observed among $27.3 \%$ of the participants of which $22.1 \%$ were overweight and $5.2 \%$ were obese. Age (OR: 2.54 ; $95 \%$ CI: 1.346-4.823); ethnicity, Brahmin/Chhetri (OR: 6.14; 95\% CI: 1.971-19.123) and Madhesi (OR: 4.641; 95\% CI: 1.534-14.04); and smoking (OR: 4.165; 95\% CI: 1.972-8.80) were associated with nutritional status of industrial workers. Additionally, food frequency (OR: 2.232; 95\% CI: 1.101-4.522), dietary diversity, and total calorie intake were also significantly associated with nutritional status of industrial workers. Conclusions. The study has indicated that more than one-fourth of workers of iron and steel industries in Bara District of Nepal are overweight or obese. Different sociodemographic and socioeconomic factors and lifestyle-related factors were associated with overweight and obesity. There is need for programs for industrial workers focused on nutrition education to raise awareness about nutrition-related problems and risk factors.
\end{abstract}

\section{Introduction}

Science and technology have made people's life easier, increased their life expectancies, and altered the lifestyle due to which different health problems like overweight and obesity arise [1-3]. Overnutrition has been a serious public health problem worldwide. Between 1975 and 2016, the worldwide prevalence of obesity has nearly tripled. According to the WHO, in 2016, more than one-third (39\%) of adults of age 18 years or more were overweight and $13 \%$ were obese [4]. In a developing country like Nepal, the problem of obesity and overweight is rising [5]. According to the Nepal Demographic and Health Survey 2016, more than one-sixth (17\%) of the males are overweight or obese. Of the total males, $15 \%$ are overweight and almost $3 \%$ are obese. The proportion of females who were overweight or obese was 9\% in 2006 and increased to $13 \%$ in 2011 and $22 \%$ in 2016 [6]. A recent study conducted in 2019 by the Nepal Health Research Council has found that $23.5 \%$ of the adult population are overweight, $7.2 \%$ are obese, and $30.7 \%$ are either overweight or obese [7]. Overweight/obesity has independently been the risk factors for many noncommunicable diseases such as diabetes, hypertension, and cardiovascular diseases. $[8,9]$.

Industrial development has been the basis of sustainable economic development globally, and for this, the government of Nepal has also given emphasis on the industries since 1950 [10]. Many of the industries in Nepal are agroprocessing, and very few are producing construction materials and export-oriented products [10]. According to the Nepal Labour Force Survey 2017/2018, almost 7.1 million of 
Nepal population are employed and almost one-fifth population of them were employed in agriculture, the biggest employing industry followed by trade industry (17.5 percent), and construction (13.8 percent) [11]. The concept of occupational health and safety is still new in a developing country like Nepal which mainly concentrates on occupation-related diseases [10]. The Labour Act of Nepal, 2017, has given emphasis on working hours, occupational health and safety, and use of personal protective equipment during work for the workers [12]. The area related to nutritional status of workers has not been discussed.

It is assumed that the employers spend a quarter of their lives at work, and the pressure of work may affect their eating behaviour and lifestyle at work, which may lead to overweight and obesity, and in turn, overweight/obesity may affect their performance at work and may increase risk of different chronic diseases $[13,14]$. In addition, different risk factors such as smoking, alcohol consumption, physical exercise, and other sociodemographic variables are the risk factors for overweight and obesity [15]. Some older studies conducted to assess the nutritional status among male adult workers in developing countries like India and Bangladesh showed that underweight was mostly prevalent and low overweight and obesity (less than $10 \%$ ) were present $[16,17]$. However, recent studies conducted in developing countries show that overweight and obesity among the industrial workers are in an increasing trend, i.e., more than $30 \%$ $[18,19]$.

In context of Nepal, the area for study related to assess the nutritional status of industrial workers is very new. Only research studies related to occupational diseases and the use of personal protective equipment have been conducted in case of Nepal. Hence, the objective of this study is to assess Factors Associated with the Nutritional Status among male workers of iron and steel industries in Bara District of Nepal.

\section{Methods}

2.1. Study Design, Study Population, and Sample Size. An industry-based quantitative descriptive cross-sectional study was done using a structured questionnaire cum interview schedule to assess the nutritional status and associated factors among male workers of iron and steel industries in Bara District. Bara District is one of the districts of Nepal where many industries are concentrated and consists of a higher number of iron and steel industries [20] that were chosen in this study. Informed written consent was obtained from all the participants who were above 19 years of age and agreed to participate in the study.

Sample size was calculated using

$$
n=\frac{Z^{2} \cdot P \cdot Q}{L^{2}}
$$

where $Z$ is the value at 95\% confidence level (i.e., 1.96 2), $P$ is the prevalence of obesity or overweight (17\%) [6], $Q$ is the probability of nonoccurrence of $p$ (i.e., $1-P$ ), and $L$ is the estimated error $(5 \%$ or 0.05$)$.

This gives the sample size of 271 with a nonresponse rate of $20 \%$. There were a total of 11 iron and steel industries in
Bara District [21]. Out of the total 11, four industries were randomly selected for the study. The selected industries with number of workers are given in Table 1 .

For selecting total samples from each industry, the population proportionate sampling method was used. The samples were selected randomly in the industries by grouping the respondents into sedentary, moderate, and heavy workers by the population proportionate sampling method (Table 1). Out of the total samples, 57 sedentary workers, 180 moderate workers, and 34 heavy workers were selected by the population proportionate method.

2.2. Variables. The nutritional status of the participants was determined based on the classification of the body mass index given by the WHO [22]. The dependant variable was categorized into BMI less than $25 \mathrm{~kg} / \mathrm{m}^{2}$ as normal and BMI more than or equal to $25 \mathrm{~kg} / \mathrm{m}^{2}$ as overweight/obese. Age of the industrial workers was categorised into less than 40 years and 40 years or more. Religion of the respondents was categorised into Hindu and others. Ethnicity was categorized into Brahmin/ Chhetri, Madhesi, and Dalit/Janajati. Educational status was categorised into illiterate, primary level, secondary level, and higher than secondary level. Income has been categorised based on the salary scale of the Nepal Government. According to the government of Nepal, the least salary is NPR 19480 which is used to categorise the income of the workers [23]. Smoking, alcohol, and physical exercise were categorised into "Yes" and "No." Dietary diversity was classified according to guidelines published by Kennedy et al. for measuring household and individual dietary diversity in Nutrition and Consumer Protection Division, the Food and Agriculture Organization of the United Nations in 2010, where foods are grouped into 3 categories such as lowest dietary diversity ( $\leq 3$ food groups), medium dietary diversity (4 and 5 food groups), and high dietary diversity [24]. Sedentary work was measured by one questionnaire item (i.e., "how often does your job require you to sit for long periods of time during your work-shift?") having a five-part Likert response set (all, most, some, little of the time, and never). For this analysis, the responses were grouped into high (all and most); middle (some); and low (little and never) [25]. Figure 1 shows the conceptual framework of the study.

2.3. Instrumentation and Data Collection. Stadiometer, Uniscale, and pretested structured questionnaire were tools, and anthropometric measurement, observation, interview and calculation were techniques used for the study. A faceto-face interview was conducted by the investigators themselves in local language of the respondents in the industries for assurance of data quality. The weight of the participants was measured in kilogram, and height was measured in the unit $\mathrm{cm}$ with nearest $0.1 \mathrm{~cm}$. The 24-hour dietary recall method was used to calculate the total calories of the participants using a set of prestandardized vessels (cups). 
TABLE 1: Sample size of the study.

\begin{tabular}{|c|c|c|c|c|c|c|c|c|}
\hline \multirow{2}{*}{ Industry no. } & \multicolumn{4}{|c|}{ Total number of workers } & \multicolumn{4}{|c|}{ Samples selected } \\
\hline & Sedentary & Moderate & Heavy & Total & Sedentary & Moderate & Heavy & Total \\
\hline 1 & 179 & 565 & 106 & 850 & 33 & 104 & 20 & 157 \\
\hline 2 & 97 & 306 & 57 & 460 & 18 & 56 & 11 & 85 \\
\hline 3 & 19 & 60 & 11 & 90 & 3 & 11 & 2 & 16 \\
\hline 4 & 15 & 46 & 9 & 70 & 3 & 9 & 1 & 13 \\
\hline Total & 310 & 977 & 183 & 1470 & 57 & 180 & 34 & 271 \\
\hline
\end{tabular}

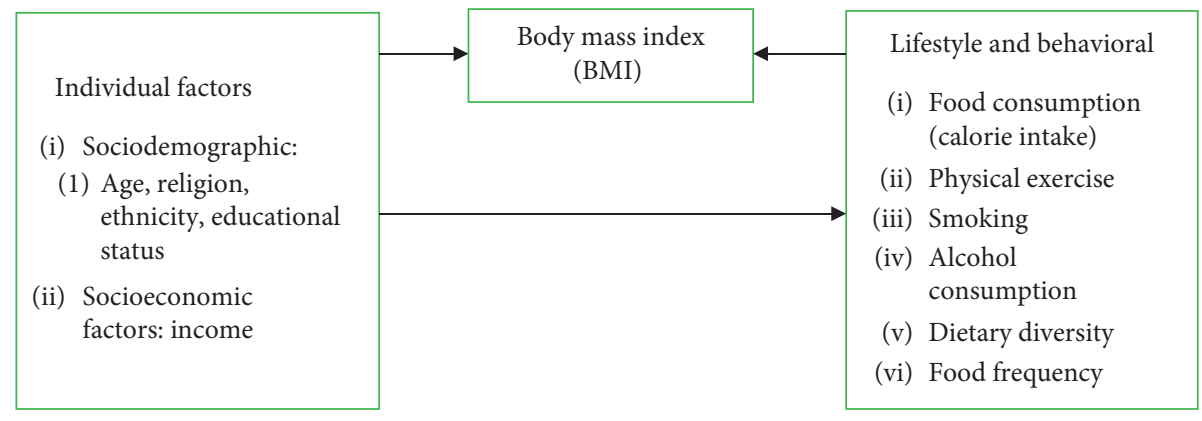

Figure 1: Conceptual framework of the study.

2.4. Statistical Analysis. The data were recorded in Microsoft Excel sheet and were analyzed using Statistical Package for Social Sciences version 23. A descriptive analysis was done using mean, frequency, percentage, and standard deviation. Bivariate analysis was done using the chi-square test for categorical variables, and the $t$-test was used for numeric variables. Variables showing significance in bivariate analysis were included in the multivariate regression model. Significance level was observed at $P$ value less than 0.05 .

2.5. Ethical Consideration. Ethical consideration was obtained from the Research Committee of the College of Applied Food and Dairy Technology, Purbanchal University. Similarly, the consent was obtained from the administration section of the selected industries. The informed written consent from randomly selected individuals was also obtained during the assessment of nutritional status.

\section{Results}

Table 2 shows the sociodemographic characteristics of the participants. Among the total participants, more than half (55\%) were below 40 years of age and more than nine-tenth (94.8\%) of the participants followed Hindu religion. Almost half $(46.9 \%)$ of the participants were Madhesi followed by Brahmin/Chhetri and Dalit/Janajati. More than three-fourth of the respondents were literate, and the proportion of participants with secondary level education was higher (39.1\%). In Nepal, the lowest government salary scale is NPR. 19480. More than two-thirds (73.9\%) of the participants had salary higher than the lowest government scale.

Table 3 shows the lifestyle nutrition-related behaviour of the participants. Almost $22 \%$ of the participants were recent smokers, and almost half (48\%) used to drink
TABLE 2: Sociodemographic and socioeconomic characteristics of the participants $(N=271)$.

\begin{tabular}{|c|c|c|}
\hline Characteristics & Frequency & Percentage \\
\hline \multicolumn{3}{|l|}{ Age $($ median $=37, \mathrm{SD}=8.2)$} \\
\hline Less than 40 & 149 & 55 \\
\hline More than or equal to 40 & 122 & 45 \\
\hline \multicolumn{3}{|l|}{ Religion } \\
\hline Hindu & 257 & 94.8 \\
\hline Others & 14 & 4.2 \\
\hline \multicolumn{3}{|l|}{ Ethnicity } \\
\hline Brahmin/Chhetri & 97 & 35.8 \\
\hline Madhesi & 127 & 46.9 \\
\hline Dalit/Janajati & 47 & 17.3 \\
\hline \multicolumn{3}{|l|}{ Educational status } \\
\hline Illiterate & 57 & 21 \\
\hline Primary & 82 & 30.3 \\
\hline Secondary & 106 & 39.1 \\
\hline Higher than secondary & 26 & 9.6 \\
\hline \multicolumn{3}{|l|}{$\begin{array}{l}\text { Income }(\text { median }=\text { NPR. } 25000, \\
S D=16110.45)\end{array}$} \\
\hline Less than NPR. 19480 & 73 & 26.9 \\
\hline More than NPR. 19480 & 198 & 73.9 \\
\hline
\end{tabular}

alcohol. Only 22.5 percent of the participants used to do physical exercise. Regarding type of work, more than twothirds $(66.4 \%)$ of the participants were middle level sedentary workers. The food frequency of $62.4 \%$ participants was more than or equal to 4 . More than half $(56.8 \%)$ participants used to take 4-6 diverse food, and almost $20 \%$ used to take less diverse food.

Figure 2 shows the nutritional status of the participants in which more than two-thirds $(67.5 \%)$ were normal. More than three-fourths $(27.3 \%)$ of the participants had BMI above normal. 
TABLE 3: Lifestyle and nutritional behavioural characteristics $(N=271)$.

\begin{tabular}{lcc}
\hline Characteristics & Frequency & Percentage \\
\hline Smoking & & \\
$\quad$ Yes & 59 & 21.8 \\
$\quad$ No & 212 & 78.2 \\
Alcohol & 130 & \\
$\quad$ Yes & 141 & 52 \\
$\quad$ No & & \\
Physical exercise & 61 & 22.5 \\
$\quad$ Yes & 210 & 77.5 \\
$\quad$ No & & \\
Sedentary work & 57 & 21.0 \\
$\quad$ High & 180 & 66.4 \\
$\quad$ Middle & 34 & 12.5 \\
$\quad$ Low & & \\
Food frequency & 102 & 37.6 \\
$\quad$ Less than 4 & 169 & 62.4 \\
$\quad$ More than or equal to 4 & & \\
Dietary diversity & 53 & 19.6 \\
$\quad$ Less than 4 & 154 & 56.8 \\
$\quad$ 4-6 & 64 & 23.6 \\
$\quad$ More than 6 \\
Body mass index: (mean =23.72,
\end{tabular}

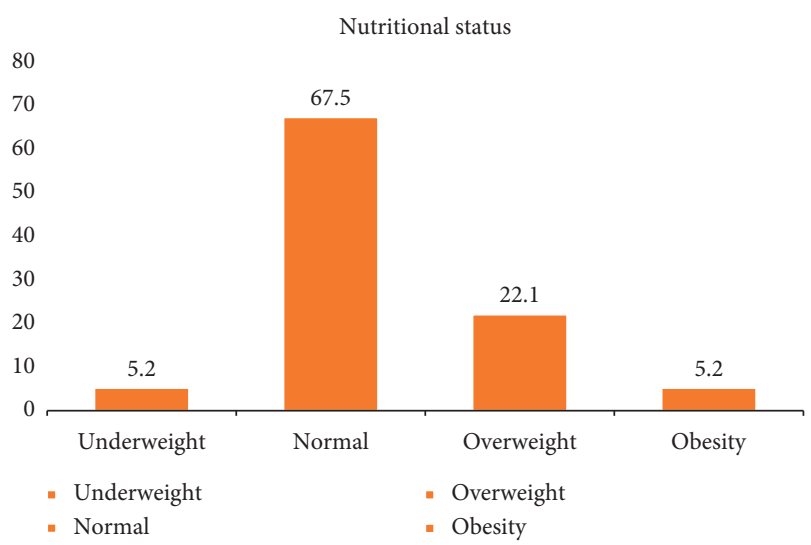

Figure 2: Nutritional status of the participants.

Table 4 shows the bivariate and multivariate analysis of the nutritional status of the participants with different variables. Overweight/obesity was significantly associated with age of the participants in both bivariate and multivariate analyses. In multivariate, participants of age more than or equal to 40 were 2.54 (1.346-4.823) times more likely to be overweight/obese than the participants below 40 years of age. Religion was not significantly associated with nutritional status. Brahmins/Chhetri and Madhesi were more overweight/obese than the participants of Dalit/Janajati ethnicity. Brahmin/Chhetri were 6.14 (1.971-19.123), and Madhesi were 4.641 (1.534-14.04) times more overweight/ obese than the Dalits/Janajati. No significant association was seen between nutritional status and education level of the participants. Participants with lower income were 1.5 times more overweight/obese than the participants with higher income, but it was statistically insignificant.

The participants who smoke were likely to be 4.165 (1.972-8.800) times more overweight/obese than the nonsmokers. Statistical significance was seen between alcohol and overweight/obesity in bivariate analysis, but it was near to significant in multivariate analysis. The participants who did not do physical exercise were 2.23 (1.068-4.680) times more overweight/obese, and it was significant with the nutritional status in the bivariate but was not significant in the multivariate analysis. The participants with low sedentary work were more likely to be overweight/obese than the middle and low sedentary workers, and it was statistically significant $(P<0.05)$. The participants having food frequency more than or equal to 4 was statistically significant with OR: 2.232 (1.101-4.522). Workers having more than 6 diverse food was significant with the nutritional status and were 3.679 (1.384-9.782) more overweight/obese than workers having 3 or less diverse food.

Table 5 shows the association between total calorie intake by the workers and nutritional status in which nutritional status of the workers was significantly associated with total calorie intake $(P$ value $<0.001)$.

\section{Discussion}

The aim of the study was to find out the factors associated with the nutritional status of the male workers of iron and steel industries in Bara District of Nepal.

In this study, the prevalence of overweight and obesity was $22.1 \%$ and $5.2 \%$, respectively. According to the Nepal Demographic and Health Survey 2016, the prevalence is lower than this study with $15 \%$ overweight and $3 \%$ obese [6]. The prevalence is lower as the survey was done among general people. The proportion of overweight is almost equal to a study carried out among government school teachers in Srinagar, India [26]. A study done among Kuwait Oil Company (KOC) employees revealed that the overall prevalence of overweight and obesity among KOC employees was 75\% which is highly greater than the prevalence of this study [9]. The higher prevalence may be due to the nutritional habits of the workers and type of work in Kuwait oil company workers. A cross-sectional study conducted in Brazil among workers of different industries found that $19 \%$ of the male workers were obese and $42 \%$ were overweight which is almost double than our study [1]. Another study conducted in Kanpur India among workers working in the knitting industry revealed that $11 \%$ of the workers were overweight which is lower than our study and $10 \%$ were obese [27]. A study conducted among US workers showed that $27.7 \%$ of the workers met the BMI criteria of obesity which is higher than this study [28]. The dissimilar findings may be due to different lifestyle and nutritional habits of workers in the US as compared to Nepal. The obesity in general people in the US is higher (42.4\%) than that of Nepal [29]. 
TABLE 4: Bivariate and Multivariate logistic analysis of the nutritional status of the participants.

\begin{tabular}{|c|c|c|c|c|c|c|}
\hline \multirow{2}{*}{ Characteristics } & \multicolumn{2}{|c|}{ Nutritional status } & \multirow{2}{*}{ COR $(95 \% \mathrm{CI})$} & \multirow{2}{*}{$P$ value } & \multirow{2}{*}{ AOR $(95 \% \mathrm{CI})$} & \multirow{2}{*}{$P$ value } \\
\hline & Normal & Overweight/obesity & & & & \\
\hline \multicolumn{7}{|l|}{ Age } \\
\hline Less than 40 & 120 & 28 & 1 & & 1 & \\
\hline More than or equal to 40 & 77 & 46 & $2.56(1.47-4.43)$ & $0.001^{*}$ & $2.548(1.346-4.823)$ & $0.004^{*}$ \\
\hline \multicolumn{7}{|l|}{ Religion } \\
\hline Hindu & 188 & 69 & 1 & & & \\
\hline Others & 9 & 5 & $1.51(0.49-4.67)$ & 0.471 & & \\
\hline \multicolumn{7}{|l|}{ Ethnicity } \\
\hline Brahmin/Chhetri & 65 & 32 & $3.36(1.294-8.747)$ & $0.013^{*}$ & $6.14(1.971-19.123)$ & $0.002^{*}$ \\
\hline Madhesi & 91 & 36 & $2.703(1.056-6.918)$ & $0.038^{*}$ & $4.641(1.534-14.04)$ & $0.007^{*}$ \\
\hline Dalit/Janajati & 41 & 6 & 1 & & 1 & \\
\hline \multicolumn{7}{|l|}{ Educational status } \\
\hline Illiterate & 37 & 20 & 1 & & & \\
\hline Primary & 65 & 17 & $0.484(0.226-1.037)$ & 0.062 & & \\
\hline Secondary & 78 & 28 & $0.664(0.332-1.330)$ & 0.248 & & \\
\hline Higher than secondary & 17 & 9 & $0.979(0.37-2.59)$ & 0.967 & & \\
\hline \multicolumn{7}{|l|}{ Income } \\
\hline Less than NPR. 19480 & 48 & 25 & $1.584(0.886-2.832)$ & 0.121 & & \\
\hline More than NPR. 19480 & 149 & 49 & 1 & & & \\
\hline \multicolumn{7}{|l|}{ Smoking } \\
\hline Yes & 32 & 27 & $2.92(1.616-5.43)$ & $<0.001^{*}$ & $4.165(1.972-8.800)$ & $<0.001^{*}$ \\
\hline No & 165 & 47 & 1 & & 1 & \\
\hline \multicolumn{7}{|l|}{ Alcohol } \\
\hline Yes & 85 & 45 & $2.045(1.185-3.52)$ & $0.010^{*}$ & $1.841(0.975-3.479)$ & 0.060 \\
\hline No & 112 & 29 & 1 & & 1 & \\
\hline \multicolumn{7}{|l|}{ Physical exercise } \\
\hline Yes & 51 & 10 & 1 & & 1 & \\
\hline No & 146 & 64 & $2.236(1.068-4.680)$ & $0.030^{*}$ & $1.897(0.787-4.569)$ & 0.154 \\
\hline \multicolumn{7}{|l|}{ Sedentary work } \\
\hline High & 31 & 26 & 1 & & 1 & \\
\hline Middle & 142 & 38 & $0.319(0.170-0.60)$ & $<0.001^{*}$ & $0.269(0.126-0.575)$ & $0.001^{*}$ \\
\hline Low & 24 & 10 & $0.497(0.201-1.226)$ & 0.129 & $0.246(0.083-0.732)$ & $0.012^{*}$ \\
\hline \multicolumn{7}{|l|}{ Food frequency } \\
\hline Less than 4 & 84 & 18 & 1 & & 1 & \\
\hline More than or equal to 4 & 113 & 56 & $2.313(1.267-4.220)$ & $0.006^{*}$ & $2.232(1.101-4.522)$ & $0.026^{*}$ \\
\hline \multicolumn{7}{|l|}{ Dietary diversity } \\
\hline Less than 4 & 42 & 11 & 1 & & 1 & \\
\hline $4-6$ & 120 & 34 & $1.082(0.503-2.326)$ & 0.840 & $0.955(0.390-2.337)$ & 0.919 \\
\hline More than 6 & 35 & 29 & $3.164(1.385-7.229)$ & $0.006^{*}$ & $3.679(1.384-9.782)$ & $0.009^{*}$ \\
\hline
\end{tabular}

COR, crude odds ratio; AOR, adjusted odds ratio; $\mathrm{CI}$, confidence interval; ${ }^{*} P$ value $<0.05$.

TABLE 5: Independent $t$-test of nutritional status with total energy intake (total calories per day).

\begin{tabular}{lcccc}
\hline Characteristics & Mean & SD & CI & $P$ value \\
\hline $\begin{array}{l}\text { Normal } \\
\begin{array}{l}\text { Overweight/ } \\
\text { obesity }\end{array}\end{array}$ & 2085.56 & 312.037 & $\begin{array}{c}-389.756 \text { to } \\
-212.100\end{array}$ & $<0.001^{*}$ \\
\hline
\end{tabular}

CI, confidence interval, ${ }^{*} P<0.05$.

Age was significantly associated with the nutritional status in this study, and it is an evidence-based fact [30]. Similar type of result was shown by a study conducted in the US among different industrial workers [28]. Another study conducted among Japanese workers also revealed similar result [31]. Religion and ethnicity were also significant with nutritional status. The workers of upper ethnicity were more likely to be overweight/obese than the workers of lower ethnicity as the people of upper class have higher income than the Dalits/Janajatis. In a study conducted in the US reveled that non-Hispanic Asians were less likely to be obese than the workers with other ethnicity [28]. A survey conducted in India also supported the finding of this study [32].

Education was not associated with overweight/obesity of the workers in this study and is supported by other studies $[33,34]$. The illiterate workers may not have knowledge related to risk factors of overweight and obesity. In this study, the illiterate people had high alcohol consumption and low physical exercise than the literate. A study conducted among US workers showed that education was 
significant with the nutritional status of the workers [28]. Income was not significant with the nutritional status and is in agreement with other studies $[33,35]$. The workers with low income also used to consume higher calories than the workers with high income, resulting in high prevalence of overweight and obesity. In a developing country like Nepal due to urbanization, diets rich in fibre and complex carbohydrates are being replaced by the diets rich in sugars and fats, resulting in increased overweight and obesity [36]. Data also have shown that in cost constraint situation, people prefer food higher in the proportion of energy derived from cereals, sweets, and added fats rather than form vegetables and fruits [37].

Smoking was significantly related to nutritional status of factory workers with $P$ value less than 0.001 . The study is supported by a cross-sectional study carried out in the UK among general people, which showed that current heavy smokers ( $>20$ cigarettes per day) were more likely to be obese than both moderate (10-20 cigarettes per day) and light $(<10$ cigarettes per day) smokers, and moderate smokers were more likely to be obese than light smokers [38]. A meta-analysis done by Dallongevilli et al. found that smokers declared significantly higher intakes of energy, total fat, saturated fat, cholesterol, and alcohol than nonsmokers [39]. Consumption of alcohol was significant in bivariate analysis and is supported by a Nigerian study [33]. Consumption of alcohol was not significant in multivariate analysis. Other studies carried also supported the finding $[31,40]$. Another study conducted among Spanish graduates was not in agreement with this study which may be differences between the type of people and the type of work [34]. Physical exercise was significantly associated with prevalence of overweight/obesity in bivariate analysis. The study is supported by the finding of a cross-sectional study conducted in Ghana and Nigeria [33,41]. The result was not in agreement with the same study conducted in Ghana in multivariate analysis [41]. The workers with age less than 40 years are more likely to do physical exercise than the older workers in the study.

In this study, sedentary work was significant with nutritional status and is in agreement with a study conducted in the US in which long sitting time was significantly associated with BMI of the participants [42] but was not significant in a study conducted in Ghana [41]. Another study conducted among US workers supported the finding [25]. According to the WHO, higher the sedentary work, more the risk of being overweight or obese in people with sedentary lifestyle [43]. Food frequency was significantly associated with overweight/obesity and is in agreement with the study conducted in Kerala among geriatric population [44]. A survey conducted in the US which used the data from the USDA Continuing Survey of Food Intake by Individuals (CSFII) collected in 1994-1996 supported the finding in which eating frequency of more than three times was associated with overweight or obese [45].

Dietary diversity was significantly associated with nutritional status of the workers, and the study is supported by a study carried out in Southwest China [46]. There was disagreement with another study conducted among nurses in Iran [47] which may be due to the gender differences and type of work and types of food taken. Another study conducted in Nigeria concluded that the overweight and obesity were higher in the adults with medium dietary score, but it was not significant [48]. Other studies conducted among adults of Sri Lanka and Brazil supported the findings in which excess weight gain is associated with higher dietary diverse foods $[49,50]$. In this study, the total mean calorie intake among the overweight and obese is higher which may be due to the higher diverse food. The higher diverse food may contain higher calories, resulting in the increased BMI. Total calorie intake was significantly associated with nutritional status and is supported by a study conducted in office workers of Korea [51].

The study has some limitations: it could not include female workers as there were no females working in the iron and steel industries. The risk factors related to overweight and obesity were assessed on the basis of self-reported data by the industrial workers only, without experimental measurements.

\section{Conclusion}

The study has presented high prevalence of overweight/ obesity among workers in iron and steel industries of Bara District. More importantly, findings of the study have pinpointed towards socioeconomic, sociodemographic, lifestyle, and dietary factors that may increase the risk of overweight or obesity in workers. Many of the workers lacked physical exercise and were moderate to sedentary workers. The workers who had more diverse food had increased overweight and obesity, and the higher diverse food may contain higher calories and, in absence of physical exercise, may have resulted in increased overweight and obesity.

The findings of the study show that there is need for proper nutrition education to the industrial workers which may contribute to change in the lifestyle and behaviours of the workers and should be more focused among the workers of age more than 40 years and with lower socioeconomic class. There is need for further research studies in the field of nutrition in industries in case of developing countries such as Nepal.

\section{Data Availability}

The data used to support the findings of this study are included within the supplementary information file.

\section{Conflicts of Interest}

The authors declare that they have no conflicts of interest.

\section{Authors' Contributions}

RKS was a principal investigator. He involved in the formulation of concept and design of the study, statistical analysis and interpretation of results, preparation of the manuscript, and overall supervision of the research. HPS actively assisted in data collection, analysis, management, 
and interpretation of manuscript writing. KT assisted in manuscript writing and overall critical review.

\section{Supplementary Materials}

The supplementary file contains the SPSS data used in the study. (Supplementary Materials)

\section{References}

[1] E. A. Q. Bortolozo, L. A. Pilatti, M. H. Canteri, and P. Arezes, "Nutritional composition of meals at work and its relationship with manufacturing workers' anthropometric profile and energy expenditure," DYNA, vol. 83, no. 196, pp. 86-92, 2016.

[2] K. A. D. Cocker, I. M. D. Bourdeaudhuij, and G. M. Cardon, "The effect of a multi-strategy workplace physical activity intervention promoting pedometer use and step count increase," Health Education Research, vol. 25, no. 4, pp. 608$619,2010$.

[3] J. Y. Chau, H. P. V. D. Ploeg, D. Merom, T. Chey, and A. E. Bauman, "Cross-sectional associations between occupational and leisure-time sitting, physical activity and obesity in working adults," Preventive Medicine, vol. 54, no. 3-4, pp. 195-200, 2012.

[4] World Health Organization, Obesity and Overweight, World Health Organization, Geneva, Switzerland, 2018.

[5] S. Piryani, K. P. Baral, B. Pradhan, A. K. Poudyal, and R. M. Piryani, "Overweight and its associated risk factors among urban school adolescents in Nepal: a cross-sectional study," BMJ Open, vol. 6, no. 5, Article ID e010335, 2016.

[6] Nepal Demographic and Health Survey, 2016, https://www. dhsprogram.com/pubs/pdf/fr336/fr336.pdf.

[7] Nepal Health Research Council, Population Based Prevalence of Selected Non-Communicable Diseases, Nepal Health Research Council, Kathmandu, Nepal, 2020, http://nhrc.gov.np/ wp-content/uploads/2019/07/CKD-Report-pdf-resize.pdf.

[8] B.-M. Kim, B.-E. Lee, H.-S. Park et al., "Long working hours and overweight and obesity in working adults," Annals of Occupational and Environmental Medicine, vol. 28, no. 1, 2016.

[9] T. Al-Asi, "Overweight and obesity among Kuwait oil company employees: a cross-sectional study," Occupational Medicine, vol. 53, no. 7, pp. 431-435, 2003.

[10] R. P. Gautam and J. N. Prasain, Current Situation of Occupational Safety and Health in Nepal, General Federation of Nepalese Trade Unions (GEFONT), Kathmandu, Nepal, 2011.

[11] Central Bureau of Statistics (CBS), Report on the Nepal Labour Force Survey 2017/18, https://nepalindata.com/media/ resources/items/20/bNLFS-III_Final-Report.pdf, Central Bureau of Statistics, Kathmandu, Nepal, 2019, https:// nepalindata.com/media/resources/items/20/bNLFS-III_FinalReport.pdf.

[12] Department of Labour, Government of Nepal, 2020 http://dol. gov.np/site/cms/12.

[13] Y. Yamada, M. Kameda, Y. Noborisaka, H. Suzuki, M. Honda, and S. Yamada, "Excessive fatigue and weight gain among cleanroom workers after changing from an 8-hour to a 12hour shift," Scandinavian Journal of Work, Environment \& Health, vol. 27, no. 5, pp. 318-326, 2001.

[14] P. A. Schulte, G. R. Wagner, A. Ostry et al., "Work, obesity, and occupational safety and health," American Journal of Public Health, vol. 97, no. 3, pp. 428-436, 2007.
[15] Y. Yamada, M. Ishizaki, and I. Tsuritani, "Prevention of weight gain and obesity in occupational populations: a new target of health promotion services at worksites," Journal of Occupational Health, vol. 44, no. 6, pp. 373-384, 2002.

[16] M. D. Hossain and L. Ahmed, "Quality of working life and nutritional status in a sample of industrial workers," Bangladesh Journal of Nutrition, vol. 18-19, no. 2005-2006, pp. 43-51, 2015.

[17] A. R. Kumar and S. Vali, "Anthropometric and clinical nutrition status of workers in some Indian factories," Asia Pacific Journal of Clinical Nutrition, vol. 3, no. 4, pp. 179-184, 1994.

[18] R. Ranawat and R. Mogra, "Food habits and nutrient intake among male shift workers of textile industries," International Journal of Home Science, vol. 2, no. 2, pp. 109-112, 2016.

[19] N. Harish, "Health and nutritional status of male industrial workers in Bangalore city," University of Agricultural Sciences, Bangalore, India, 2015.

[20] List of Industries Granted with Licenses to Use NS Mark on Their Products, 2020, http://nbsm.gov.np/uploads/files/List_ of_Industries_granted_with_licenses_to_use_NS_mark_on_ their_products.pdf.

[21] Department of Industry, 2018.

[22] World Health Organization, Obesity, World Health Organization, Geneva, Switzerland, 2014.

[23] New Salary Scale of All Government Employee of Nepal Published: Valid from 2076 Shrawan-Exam Sanjal, 2020, https://www.examsanjal.com/2019/new-salary-scale-of-allgovernment-employee-of-nepal-published-valid-from-2076shrawan/.

[24] G. Kennedy, T. Ballard, and M. C. Dop, Guidelines for Measuring Household and Individual Dietary Diversity, FAO, Rome, Italy, 2010.

[25] B. K. Choi, P. L. Schnall, H. Yang et al., "Sedentary work, low physical job demand, and obesity in US workers," American Journal of Industrial Medicine, vol. 53, no. 11, pp. 1088-1101, 2010.

[26] K. Amin, N. Khan, and P. Kousar, "Health and nutritional status of school teachers (with specific reference to government schools of Rawalpora, district Srinagar)," IOSR Journal of Humanities and Social Science, vol. 20, no. 10, pp. 40-42, 2015.

[27] M. Tiwari and S. Babel, "Study of health and nutritional status of the workers working in knitting industry located at Kanpur, India," Journal of Applied and Natural Science, vol. 5, no. 2, pp. 416-419, 2013.

[28] S. E. Luckhaupt, M. A. Cohen, J. Li, and G. M. Calvert, "Prevalence of obesity among US workers and associations with occupational factors," American Journal of Preventive Medicine, vol. 46, no. 3, pp. 237-248, 2014.

[29] CDC, Adult Obesity Facts-Overweight \& Obesity, CDC, Atlanta, GA, USA, 2020, https://www.cdc.gov/obesity/data/ adult.html.

[30] Statista, Overweight Prevalence by Age Worldwide 2019, Statista, Hamburg, Germany, 2019, https://www.statista.com/ statistics/1065605/prevalence-overweight-people-worldwideby-age/.

[31] M. Ishizaki, Y. Morikawa, H. Nakagawa et al., "The influence of work characteristics on body mass index and waist to hip ratio in Japanese employees," Industrial Health, vol. 42, no. 1, pp. 41-49, 2004.

[32] S. Pengpid and K. Peltzer, "Prevalence and correlates of underweight and overweight/obesity among women in India: results from the national family health survey 2015-2016," Diabetes, Metabolic Syndrome and Obesity: Targets and Therapy, vol. 12, pp. 647-653, 2019. 
[33] G. T. Fadupin, A. Adeoye, and O. Ariyo, "Lifestyle and nutritional status of urban school teachers in Ibadan, Nigeria," Nigerian Journal of Nutritional Sciences, vol. 35, no. 1, pp. 86-94, 2014.

[34] M. A. Alcácera, I. Marques-Lopes, M. Fajó-Pascual et al., "Lifestyle factors associated with BMI in a Spanish graduate population: the SUN study," Obesity Facts, vol. 1, no. 2, pp. 80-87, 2008.

[35] C. L. Ogden, T. H. Fakhouri, M. D. Carroll et al., "Prevalence of obesity among adults, by household income and education-United States, 2011-2014," Morbidity and Mortality Weekly Report, vol. 66, no. 50, pp. 1369-1373, 2017.

[36] A. Vaidya, S. Shakya, and A. Krettek, "Obesity prevalence in Nepal: public health challenges in a low-income nation during an alarming worldwide trend," International Journal of Environmental Research and Public Health, vol. 7, no. 6, pp. 2726-2744, 2010.

[37] S. A. Tanumihardjo, C. Anderson, M. Kaufer-Horwitz et al., "Poverty, obesity, and malnutrition: an international perspective recognizing the paradox," Journal of the American Dietetic Association, vol. 107, no. 11, pp. 1966-1972, 2007.

[38] S. Dare, D. F. Mackay, and J. P. Pell, "Relationship between smoking and obesity: a cross-sectional study of 499,504 middle-aged adults in the UK general population," PLoS One, vol. 10, no. 4, Article ID e0123579, 2015.

[39] J. Dallongeville, N. Marécaux, J.-C. Fruchart, and P. Amouyel, "Cigarette smoking is associated with unhealthy patterns of nutrient intake: a meta-analysis," The Journal of Nutrition, vol. 128, no. 9, pp. 1450-1457, 1998.

[40] S. S. Klobodu, M. Steiner-Asiedu, E. Colecraft, and A. K. Anderson, "Nutritional status of alcoholics in periurban areas of the greater Accra region of Ghana," African Journal of Food, Agriculture, Nutrition and Development, vol. 14, no. 3, 2014.

[41] P. N. O. Addo, K. M. Nyarko, S. O. Sackey, P. Akweongo, and B. Sarfo, "Prevalence of obesity and overweight and associated factors among financial institution workers in Accra Metropolis, Ghana: a cross sectional study," BMC Research Notes, vol. 8, no. 1, pp. 1-8, 2015.

[42] T.-C. Lin, T. K. Courtney, D. A. Lombardi, and S. K. Verma, "Association between sedentary work and BMI in a US national longitudinal survey," American Journal of Preventive Medicine, vol. 49, no. 6, pp. e116-e123, 2015.

[43] WHO, "Physical inactivity a leading cause of disease and disability, warns WHO," Journal of Advanced Nursing, vol. 39, p. 518, 2002, http://www.ncbi.nlm.nih.gov/pubmed/ 12365404 .

[44] J. Binu and R. Harnagle, "A study on the prevalence of overweight and obesity and its influencing factors among rural geriatric population in Kerala," International Journal of Current Microbiology and Applied Sciences, vol. 3, no. 9, pp. 284-293, 2014.

[45] N. C. Howarth, T. T.-K. Huang, S. B. Roberts, B.-H. Lin, and M. A. McCrory, "Eating patterns and dietary composition in relation to BMI in younger and older adults," International Journal of Obesity, vol. 31, no. 4, pp. 675-684, 2007.

[46] Q. Zhang, X. Chen, Z. Liu, D. S. Varma, R. Wan, and S. Zhao, "Diet diversity and nutritional status among adults in southwest China," PLoS One, vol. 12, no. 2, Article ID e0172406, 2017.

[47] K. Mirzaei, "The association between dietary diversity with shift work among the nurses," Journal of Nursing \& Care, vol. 7, no. 4, 2018.
[48] K. Omage and V. O. Omuemu, "Assessment of dietary pattern and nutritional status of undergraduate students in a private university in southern Nigeria," Food Science \& Nutrition, vol. 6, no. 7, pp. 1890-1897, 2018.

[49] R. Jayawardena, N. M. Byrne, M. J. Soares, P. Katulanda, B. Yadav, and A. P. Hills, "High dietary diversity is associated with obesity in Sri Lankan adults: an evaluation of three dietary scores," BMC Public Health, vol. 13, no. 1, p. 314, 2013.

[50] R. Sichieri, "Dietary patterns and their associations with obesity in the Brazilian city of Rio de Janeiro," Obesity Research, vol. 10, no. 1, pp. 42-48, 2002.

[51] J.-Y. Kim, Y.-H. Park, and E.-N. An, "The relationship between lifestyles and obesity of office workers in Korea," International Journal of Control and Automation, vol. 8, no. 10, pp. 349-360, 2015. 